\title{
La afinidad electiva entre educación artística y sociedad: apuntes de análisis desde el caso chileno*
}

\author{
The Elective Affinity between Arts Education and Society: Notes \\ for Analysis Based on the Case of Chile
}

Tomás Peters** , Marta Hernández***

\section{RESUMEN}

Este artículo elabora la hipótesis de que existe una afinidad electiva entre un mayor acceso a talleres de educación artística y los beneficios que esto conlleva, tanto para los individuos que participan en ellos como también para la sociedad en su conjunto. A partir de análisis estadísticos de las Encuestas Nacionales de Participación y Consumo Cultural de 2009, 2012 y 2017 del Consejo Nacional de la Cultura y las Artes - hoy Ministerio de las Culturas, las Artes y el Patrimonio-, este artículo ofrece evidencia empírica sobre la relación entre participación en programas de educación artística, principalmente en la forma de talleres artísticos, tanto formales como informales, y las opiniones o valoraciones que los chilenos despliegan sobre la democracia, la sociabilidad, la tolerancia al conflicto y la formulación de sus proyectos biográficos.

\section{ABSTRACT}

This article proposes the hypothesis of an elective affinity existing between greater access to arts education workshops and the benefits that this brings about, both for the individuals partici-
Palabras clave: educación artística, sociedad, afinidad electiva, democracia, Chile
Key words: arts education, society, elective affinity, democracy, Chile

\footnotetext{
* Este artículo es resultado del Fondecyt de Postdoctorado No 3180346: "Participación y consumo cultural en Chile en el siglo XXI: prácticas emergentes, nuevas desigualdades y redefiniciones teóricoculturales", ANID, Chile.

** Doctor en Estudios Culturales por la Universidad de Londres. Académico del Instituto de la Comunicación e Imagen, Universidad de Chile. Chileno. Correo: tpeters@ uchile.cl Orcid: https://orcid.org/0000-0002-0765-917X

*** Doctora @ en Filosofía, Mención Teoría e Historia del Arte por la Universidad de Chile. Docente de la Universidad Academia de Humanismo Cristiano. Chilena. Correo: marta.hernandez@uacademia.cl Orcid: https://orcid.org/0000-0002-2476-3702
} 
pating in them and for society as a whole. Based on a statistical analysis of the National Cultural Participation and Consumption Surveys from 2009, 2012, and 2017, of the National Council for Culture and the Arts - now the Ministry of Culture, Arts, and Heritage -, this articles offers empirical evidence of the relationship between participation in arts education programs, primarily in the form of formal and informal art workshops, and the opinions and perspectives of Chileans with respect to democracy, sociability, tolerance of conflict, and the formulation of their biological projects. 


\section{Introducción}

La trayectoria histórica de la educación artística está atravesada por tendencias teóricas, discusiones políticas, transformaciones del campo artístico y ciclos socioculturales en permanente mutación (Rojas \& Del Valle, 2020). En su interrelación, se han ido trazando modelos, métodos y esquemas de trabajo que han servido para definir directrices complejas y en constante discusión. A través del ejercicio de la educación artística, la sociedad ha buscado otorgar a sus ciudadanos conocimientos sobre el quehacer artístico y su historia, así como también aprendizajes de técnicas y desarrollo de habilidades útiles a las demandas de los tiempos. Educación y arte se complementan, no tan solo como un marco de enseñanzas y aprendizajes que se definen, en la mayoría de los contextos, según criterios estandarizados y disciplinarios, sino también para reflexionar sobre los significados culturales, identitarios y de sentido de una sociedad. En otros términos, la educación artística, tanto formal como informal, introduce en el marco general de educación un esquema de pensamiento y cuestionamiento acerca de las diversas dimensiones de la realidad social, política, cultural, económica, ecológica, etcétera, de una comunidad. Visibilizar, conceptualizar, experienciar, decodificar y reflexionar un fenómeno social contemporáneo desde una forma artística - o con una sensibilidad estética一, resulta ser un eje central de la educación artística del presente y también de las políticas públicas (Alvarado \& Marini, 2020). Sin embargo, lograr esta apuesta crítica ha sido el resultado de múltiples propuestas, intentos y discusiones sobre el rol del arte en la educación. Entre ambos ámbitos se establecen lógicas procedimentales complejas y en permanente discusión.

El presente artículo tiene como objetivo discutir esas consideraciones históricas, teóricas y políticas de la educación artística y cómo esta se interrelaciona con otras dimensiones socioculturales, tales como sociabilidad, percepción democrática, tolerancia al conflicto y reflexividad biográfica. A partir de análisis estadísticos de la Segunda Encuesta Nacional de Participación y Consumo Cultural de 2009 y la Cuarta Encuesta Nacional de Participación Cultural del 2017 del Consejo Nacional de la Cultura y las Artes - hoy Ministerio de las Culturas, las Artes y el Patrimonio-, este artículo ofrece evidencia empírica sobre la relación entre participación en programas de educación artís- 
tica, principalmente en la forma de talleres artísticos, tanto formales como informales, y las opiniones o valoraciones que los chilenos despliegan sobre su sociedad, la tolerancia al conflicto y la formulación de sus proyectos biográficos. En su conjunto, este artículo se propone elaborar la hipótesis de lectura sobre las afinidades que existen entre un mayor acceso a talleres de educación artística y los "beneficios" que esto conlleva tanto para los individuos que participan en ellos, como también para la sociedad en su conjunto.

\section{Marco teórico. Elementos histórico-reflexivos de la educación artística}

Desde el siglo XIX el arte ha servido como un mecanismo de enseñanza de habilidades técnicas y cognitivas, orientadas a apoyar los procesos de industrialización y complejización de la sociedad moderna (Efland, 1990). A través de la enseñanza del dibujo, la copia de ilustraciones y el uso de las "manos ociosas", los niños y jóvenes lograban adquirir mayores niveles de coordinación motora, así como también métodos de trabajo y técnicas necesarias para responder a las necesidades mecánicas y crecientes del trabajo industrial. De la misma forma, el dibujo cumplía un rol educativo, a través de la repetición de motivos religiosos y/o situaciones morales que ayudaban a estructurar los modos de comportamiento social del sujeto moderno. Si bien la cobertura de la enseñanza, tanto en Europa como en América, era limitada a los más aventajados, durante la primera mitad del siglo XIX surgieron los primeros manuales o documentos dedicados a la enseñanza del diseño y del dibujo a nivel masivo. Conceptos como "composición", "proporción", "ángulo", "simetría", "volumen", etcétera, se inscribieron como materias fundamentales en los círculos de enseñanza de los países industrializados, y se incluyeron en los primeros planes educacionales formales.

Chile, como una naciente nación, no se quedó ausente de estos procesos (Errázuriz, 1994; Villegas et al., 2017). Desde sus tiempos como país independiente, las asignaturas de dibujo lineal y geometría quedaron curricularmente adscritas a los planes de enseñanza técnica y matemática, y tenían como objetivo formar a los niños y jóvenes de clase baja y media - principalmente en horario vespertino- en las virtudes de la observación, la distinción, el dimensionado y la medi- 
ción de objetos, cuerpos y figuras gráficas, así como también para mejorar la escritura, entre otros objetivos anexos. A diferencia del dibujo técnico-profesional, caracterizado por el método del ensayo y error, la educación del dibujo artístico se dictaba en escuelas de clase alta, en horarios diurnos, y cumplía un rol de formación de la mente y del aumento progresivo de la complejidad de las técnicas de la representación y la proporcionalidad, así como también de la experimentación y el descubrimiento estético.

Al lograr la destreza en la imitación de la forma, los niños y jóvenes de clases más acomodadas podían adquirir habilidades intelectuales para su desempeño futuro. Para apoyar esos propósitos, el Estado de Chile fundó, en 1849, tanto la Academia de Pintura de Santiago, conformada principalmente con profesores extranjeros, como la Escuela de Artes y Oficios, con el objetivo de fomentar la enseñanza de las artes y mejorar las condiciones generales de desarrollo intelectual del país (Zamorano, 2007). En cada una de estas instituciones se dio inicio a un esquema de enseñanza ad hoc a los tiempos y se introdujo, al finalizar el último cuarto del siglo XIX, nuevos contenidos teóricos (conceptos de "arte", "procesos culturales", "historia", etcétera) al currículo histórico del dibujo. Si bien estas nuevas materias fueron incluidas en los esquemas escolares formales, fueron las elites nacionales las que se vieron beneficiadas. El resto de la población mantuvo, en niveles generales, el desarrollo del dibujo vinculado a las habilidades técnicas y manuales asociadas al plan histórico.

La evolución de la educación en todo el mundo significó, al mismo tiempo, reconocer las diferencias cognitivas y evolutivas de niños, jóvenes y adultos. Con la expansión de la psicología evolutiva, a finales del siglo XIX, y gracias a las investigaciones acerca de a los procesos biológicos y cognitivos, comenzaron a diferenciarse cualitativamente las nociones de "niñez" (e infancia) y "adolescencia" respecto de la figura del "adulto". Esto tuvo como repercusión comprender las habilidades y necesidades de cada uno de ellos por separado, así como también estimar sus diferencias emocionales y cognitivas según los tiempos biográficos. De hecho, a mediados del siglo XX ya estaba expandida la idea de que el arte era una herramienta de expresión libre y creativa. Según los postulados que, desde la década de 1930, elaboró John Dewey, el arte era una experiencia que servía como vehículo para desarrollar ha- 
bilidades creativas generales y el pensamiento crítico (Dewey, 1980). A través del planteamiento de trabajar el arte por el arte, cada niño podía crecer mental, física y socialmente. De esta forma, el ámbito de la educación artística comenzó a tomar un cariz terapéutico-expresivo y necesitó de postulados pedagógicos y metodológicos acordes con ese régimen de sentido.

Durante la primera mitad del siglo XX se diseñaron y establecieron marcos de enseñanza orientados a fomentar el crecimiento emocional y cognitivo de los niños, y en discutir la introducción de nuevas técnicas para la expresión artística (reemplazando el lápiz por pinceles y colores, y fomentando el uso de la manualidad). Desde entonces, el tiempo libre y el aumento del interés por las artes generó el reconocimiento de la educación artística como una actividad recreacional orientada al fomento individual, y no como un acercamiento al fenómeno artístico en síy en relación con los contextos sociales de producción.

Este nuevo paradigma de enseñanza tuvo repercusiones en el contexto nacional. Influenciada por las corrientes norteamericanas, a mediados del siglo XX se dio inicio a la "escuela renovada" (Miranda \& Espinoza, 2015). En 1949, la asignatura de Dibujo, dictada en la Educación Básica, pasó a llamarse "Artes Plásticas" y se dio especial énfasis en la experiencia, creatividad y expresividad. Catorce años después, y a pesar de la fuerte resistencia por parte de sectores de la población por mantener el Dibujo Lineal para la inserción laboral, ocurriría lo mismo en la Educación Secundaria. En ella la asignatura de Artes Plásticas se enfocaría en la expresión visual, la autoexpresión y la apreciación estética de los jóvenes, y se solicitaría a los profesores que evaluaran la capacidad de sus estudiantes en el desarrollo de proyectos creativos y originales mediante la expresión de la afectividad. A través de la expresión del yo o de la "absoluta singularidad", los estudiantes podían reforzar sus cualidades individuales, desfavoreciendo, no obstante, la articulación entre el individuo y su contexto, lo que implicó una despolitización y la exaltación de la noción de "genio creador".

Este esquema general de sentido en la educación artística en Chile se mantuvo durante gran parte de la segunda mitad del siglo XX (Miranda \& Espinoza, 2015). Aun cuando sufrió variaciones significativas durante el periodo de la Unidad Popular, cuando las artes jugaron un 
rol fundamental en la formación del "hombre nuevo", bajo la Escuela Nacional Unificada, durante la dictadura militar sufrió cambios relevantes en su distribución horaria y temática (enfocada, por ejemplo, en resaltar los valores patrios y el paisaje nacional). En 1982 y con la promulgación del decreto 300, la asignatura perdió su carácter obligatorio en los primeros años de la enseñanza secundaria y fue reemplazada por un plan optativo entre Artes Plásticas, Música y Educación Técnico Manual. Con un carácter electivo, Artes Plásticas no solo tuvo que compartir materias cruzadas con otras disciplinas, dependiendo de cada establecimiento educacional (una liberalización de los contenidos), sino también fue eliminada de los colegios técnico-profesionales y se redujeron sus horas de clase al mínimo (Errázuriz, 1994).

Si bien hubo criterios curriculares mínimos y obligatorios en el sistema formal, al retornar la democracia resultaba difícil entender cuál era el enfoque disciplinar y didáctico que durante los últimos años se había ofrecido para la enseñanza de las artes en las escuelas del país. Debido a la flexibilización de contenidos durante la reforma de 1980, durante la década de 1990 se crearon nuevos planes y programas de educación artística en el país y a nivel general ${ }^{1}$. Al mismo tiempo, se generaron proyectos paralelos al sistema escolar, tales como Balmaceda 1215 (hoy Balmaceda Arte Joven), y posteriormente otras experiencias privadas, como CreArte y Arteduca (ambas fundadas en 2001). Sumado a la escasa claridad de la evaluación de la enseñanza artística y la lógica difusa del ejercicio de la educación artística por parte de los docentes durante la década de los noventa, se generó una tendencia a la desvalorización de la asignatura, así como también a una sensación de función recreativa antes que formativa. Varios han sido los diagnósticos que han señalado que, durante esos años, la educación general y la artística en particular sufrió una de las crisis de diseño más importantes de su historia (Gaete, Miranda \& Ramírez, 2007).

Sin embargo, durante la década del 2000 se iniciaría un nuevo impulso programático, tanto a nivel institucional como político, por la educación artística. Con la creación del Consejo Nacional de la Cultura y las Artes, en 2003, y con el surgimiento de las primeras políticas

1 Para un análisis de la renovación disciplinaria tras la reforma curricular, véase Nervi (2004). 
culturales "oficiales" del Estado de Chile, se creó una serie de programas e inversiones en materia cultural inéditos para el país: se fundaron nuevos centros culturales, se crearon consejos regionales de cultura en todo el país, se ampliaron los fondos concursables a diversas áreas del mundo artístico, se elaboraron políticas específicas para el fomento de las industrias culturales y creativas, y se gestaron programas de educación artística en el país, tales como "Okupa" (hoy derivado en los planes "Acciona" y "Centros de Creación", CECREA). Este proceso, ciertamente, estaba en línea con discusiones generales sobre la educación artística en el resto del mundo (Hermosilla, 2020).

\section{Nuevos modelos y objetivos de la educación artística a inicios del siglo XXI}

La educación artística ha estado cruzada por una serie de procesos sociales, culturales y políticos (Efland Freedman \& Stuhr, 1996). A finales del siglo XX, una serie de organismos internacionales comenzaron a discutir y difundir el concepto de "desarrollo humano" como un nuevo paradigma global que buscaba reemplazar la hegemonía reinante del desarrollo económico como única vía al bienestar social. Con el fin de fomentar la calidad de vida de las personas, la educación estaba llamada a promover un desarrollo humano general y sostenible, y la educación artística jugaba un papel significativo en ese plan (Dewey, 1980; Gardner, 1990; Efland, 1990; Efland, Freedman \& Stuhr, 1996). En ese sentido, la educación artística entregaría herramientas para enfrentar los desafíos del mundo actual, caracterizado por tensiones y desajustes estructurales que signaban a la sociedad de masas bajo las lógicas del entonces incipiente $-\mathrm{y}$ hoy expandido- capitalismo cognitivo (Ossa, 2016).

Al iniciar el siglo XXI, la educación artística no solo se ha transformado en un actor clave para reforzar comunidades y aportar a la diversidad cultural, sino también para resignificar la relación arte y sociedad (Fleming, Bresler \& O'Toole, 2015). Por ejemplo, durante esta década se ha consolidado la relación entre escuela, museo y arte, gracias a los postulados históricos de la nueva museología, así como también de la actual museología crítica (caracterizada, por ejemplo, con la documenta 12 y bienales como la del Mercosur), que proponen hacer del museo un espacio para el conocimiento y la reflexión crítica, 
así como también un lugar deliberativo en el cual la participación de la escuela, los profesores y los jóvenes cumplen un rol fundamental (Barrett, 2012; Burnham \& Kai-Kee, 2014).

En efecto, los acercamientos entre arte, educación y sociedad, identificados en el siglo XX, se han complejizado, principalmente por las características y problemáticas de una sociedad determinada por la aceleración permanente de sus lógicas operativas (Martineau, 2017). En ese sentido, durante las últimas décadas ha habido desplazamientos importantes sobre cómo se pensaron los modelos de la educación artística y cómo se discuten en el presente. Por ejemplo, se ha ido desde un modelo academicista, que recogía la tradición moderna colocando énfasis en las habilidades de representación por medio de la práctica artística, para luego avanzar al expresionista, que promovía la creatividad y la expresión de la subjetividad a través del arte. Posteriormente se ha propuesto una nueva forma de alfabetización visual, que busca explicar y enseñar códigos para entender las obras, hasta finalmente los actuales postulados de la cultura visual, que consiste en el análisis e interpretación de las imágenes como fenómeno cultural, global y contemporáneo (Mirzoeff, 2003; Hernández, 2007).

Estas perspectivas han apuntado a disolver o eliminar las distinciones y barreras que existían entre artes y educación. Ello se ha visto traducido en la importancia dada a la horizontalidad entre los actores involucrados, el énfasis en la construcción de una obra colectiva y en una propuesta que desplaza a la enseñanza formal para profundizar sentidos y contenidos abiertos y participativos (Acaso \& Megías, 2017). Esta propuesta, cercana al "giro educativo" o "giro pedagógico" de la educación artística contemporánea, ha generado nuevas discusiones en la materia. Ligado a las artes comunitarias y/o participativas, este nuevo giro ha fomentado en la educación artística un modelo dialógico, horizontal y colectivo de conocimiento que potencia al conjunto social (Fleming, Bresler \& O'Toole, 2015; Naughton, Biesta \& Cole, 2018).

Estos nuevos lineamientos han tenido cabida no solo en los currículos académicos o educacionales formales (ministeriales), sino también entre instituciones multilaterales. En la primera década del presente siglo hubo dos grandes hitos que marcaron un antes y un después en la discusión entre arte y educación: a saber, las conferen- 
cias sobre Educación Artística organizadas por la Organización de las Naciones Unidas para la Educación la Ciencia y la Cultura (UNESCO) en los años 2006 y 2010. Por una parte, la Hoja de Ruta para la Educación Artística de Lisboa, Portugal, de 2006, tuvo como objetivo explorar la contribución de la educación artística para satisfacer las necesidades de creatividad y sensibilización cultural en el siglo XXI, centrándose en las estrategias necesarias para introducir o fomentar la educación artística en el entorno de aprendizaje (UNESCO, 2006). Por su parte, "La agenda de Seúl" de 2010 reunió los resultados de la Segunda Conferencia Mundial sobre la Educación Artística, la cual tenía como objetivo sensibilizar a la comunidad internacional sobre su importancia, además de presentar proyectos concretos de buenas prácticas y fortalecer la cooperación entre los actores con el propósito de promover la diversidad cultural, el diálogo intercultural y la cohesión social (UNESCO, 2010).

Estos paradigmas educativos internacionales han tenido una recepción positiva en Chile ${ }^{2}$. Como hemos visto hasta ahora, la educación artística ha experimentado en la última década una serie de transformaciones tanto discursivas como programáticas. En septiembre de 2009, la Ley No 18.962 Orgánica Constitucional de Enseñanza de 1990, heredera de Pinochet y cuestionada fuertemente por el movimiento estudiantil de 2006, fue reemplazada por la Ley General de Educación. Este nuevo orden jurídico educativo definió, entre otras materias, a la educación artística como una tercera modalidad de formación y a la par de la científico-humanista y la técnico-profesional. Esto, junto con el cambio de la denominación de "Artes Plásticas" por "Artes Visuales", realizado algunos años antes, significó una transformación en la forma de pensar la educación artística. Si antes el enfoque disciplinar se enfocaba en la habilidades manuales y creativas de los niños, con base en el quehacer artístico, con el tiempo se ha comenzado a agregar nuevas dimensiones al área. En los últimos años la educación artística ha vivido la inclusión de nuevos contenidos, tanto teóricos como técnicos, relacionados con el uso de las tecnologías como soporte para la producción de artes digitales y mediales. A través del desarrollo de ha-

2 Para un análisis completo de los modelos, discusiones y tendencias actuales sobre la educación artística en Chile, véase Orbeta (2015) y CNCA (2013a). 
bilidades digitales, en video, cine, fotografía y multimedia, etcétera, la educación artística de la primera década del siglo XXI debía actualizarse a las lógicas de la sociedad visual y tecnológica contemporánea. De esta forma, entre los 2013 y 2015 se presentaron a la comunidad educativa las nuevas Bases Curriculares de Artes Visuales para la educación básica $\left(1^{\circ} \mathrm{a} 6^{\circ}\right.$ básico $)$ y, posteriormente, las de $7^{\circ}$ básico a $2^{\circ}$ medio. En ambas reformas se señala que, en el mundo actual, el conocimiento y la comprensión de la visualidad es determinante en la vida de los sujetos, ya que permite aprender el mundo de manera crítica, evaluando el valor y el sentido del arte y la cultura visual en sus dimensiones expresivas, comunicativas y creativas (Miranda \& Espinoza, 2015).

La "cultura visual" comenzó a ingresar entonces como una noción fundamental en la educación artística nacional. Entendida como aquellos objetos e imágenes del presente y del pasado, de la cultura ajena y propia, que conforman un universo simbólico que incluye el arte canónico, la cultura popular y los medios digitales, esta nueva propuesta abrió un nuevo capítulo en esta compleja trayectoria (Ossa, 2017).

Bajo el segundo gobierno de Michelle Bachelet se estableció el Plan Nacional de Artes en Educación, el cual ha buscado promover la educación artística en el sistema educacional, otorgándole un lugar en la formación integral, tanto emocional como cognitiva, de niños y jóvenes. En términos concretos, este Plan Nacional se ha implementado a través de talleres artísticos, equipamiento para artes visuales y música en las escuelas del país, material didáctico para la enseñanza de los objetivos curriculares, capacitaciones y programas de formación, entre otros programas específicos (Miranda \& Espinoza, 2015).

Sin embargo, en la historia reciente el organismo público que más interés político ha tomado en la educación artística ha sido el Consejo Nacional de la Cultura y las Artes, hoy Ministerio de las Culturas, las Artes y el Patrimonio. En términos generales ha seguido las recomendaciones de los organismos internacionales y ha estado en sintonía con las propuestas arriba descritas. Este hecho se aprecia, por ejemplo, en la "Caja de herramientas para la educación artística", que consiste en una serie de cinco cuadernos con fines formativos, publicados el año 2016, así como en una serie de "Cuadernos Pedagógicos", de uso en la escuela, acerca de Violeta Parra, Patricio Guzmán, Los Jaivas, Gonzalo Rojas, Raúl Ruíz, Bafona, Nemesio Antúnez, etcétera. En todos estos 
documentos se destaca la importancia de las artes para lograr una educación de calidad, así como también se presentan enfoques de educación artística e iniciativas basadas en modelos contemporáneos de trabajo que no necesariamente se enseñan en las aulas, sino también en espacios no convencionales o formales (Mincap, 2018b).

Bajo ese plan, uno de los elementos clave de estos esfuerzos públicos en educación artística ha sido lograr que esta sea un aporte concreto para la formación ciudadana y el reconocimiento de la diversidad cultural, entre otros temas. Si, como ha señalado Bamford (2009), las artes en la educación generan una serie de beneficios estructurales en la sociedad, entonces cabría preguntarse aquí sobre cómo el acceso a la educación artística en Chile (en la forma de talleres o cursos no tradicionales de arte, o fuera de la jornada escolar) se interrelaciona con otras dimensiones socioculturales, tales como sociabilidad, percepción democrática, tolerancia al conflicto y reflexividad biográfica. En otros términos, resulta importante avanzar en una pregunta sobre cómo participar en experiencias formativas artísticas no convencionales se vincula con la elaboración de visiones o lecturas crítico-reflexivas acerca de la sociedad.

\section{Metodología}

Para dar respuesta a la pregunta si existe alguna relación entre participación en programas de educación artística - principalmente en la forma de talleres artísticos tanto formales como informales- y las opiniones o valoraciones que los chilenos despliegan sobre la democracia, la tolerancia al conflicto y la formulación de sus proyectos biográficos se procedió a estudiar las estadísticas de consumo cultural realizadas en Chile desde 2009 a 2017. En un primer momento se realizó un análisis de los cambios en las prácticas de consumo cultural de los chilenos durante 2012 y 2017 a partir de la Tercera Encuesta Nacional de Participación y Consumo Cultural $2012^{3}$ (ENPCC 2012) y la Cuarta Encuesta

3 Esta encuesta se realizó a hombres y mujeres de 12 años y más, residentes de zonas urbanas de todas las regiones del país. Contó con una muestra de 8.200 casos. El margen de error muestral es de $1,08 \%$ y un $95 \%$ de confianza bajo supuesto de varianza máxima. La aplicación se realizó durante los meses de marzo y noviembre de 2011. 
Nacional de Participación Cultural $2017^{4}$ (ENPC 2017). En segundo lugar, y para dar respuesta a la pregunta específica, se analizó la Segunda Encuesta Nacional de Participación y Consumo Cultural (ENPCC 2009) de $2009^{5}$. En ella se filtró a todas las personas que habían respondido afirmativamente a alguna de las alternativas de la pregunta 112. "En los últimos 12 meses, ¿ ¿ha asistido a clases o talleres de: a) Danza o baile; b) Interpretación de instrumentos musicales; c) Teatro; d) Literatura; e) Canto; f) Cine; y g) Fotografía?". Una vez identificados los chilenos que habían participado en al menos un taller o clases de esos dominios artísticos, se realizaron análisis bivariados a partir del módulo "Percepción Sociocultural de Chile" de la misma encuesta. Esta estrategia de análisis se basa en la metodología empleada por Peters (2012) para identificar las afinidades electivas entre consumo cultural y percepción sociocultural adaptada al caso aquí analizado.

\section{Análisis. Las afinidades entre educación artística y sociedad en Chile: incursiones empíricas}

En la actualidad es obligado reconocer que los ciudadanos chilenos disponen de un mayor acceso y frecuencia a las manifestaciones artísticas y culturales, aunque esto no se refleje necesariamente en términos estadísticos (Mincap, 2018a). Como se ha visto en los últimos años, las lógicas del acceso a la cultura y las artes se han transformado radicalmente por las tecnologías de la información. Gracias a internet y las redes sociales, es posible acceder a contenidos artísticos ilimitados en todo el mundo, generando un tipo de acceso - y produccióncaracterizado por un vínculo estrecho con las pantallas digitales (esto es evidente en las formas de lectura y visualización de imágenes y videos). Sin embargo, al mismo tiempo, esto tiene efectos en las formas de acceso tradicionales. Según los datos actuales, la asistencia a este tipo de espacios ha disminuido silenciosa pero inexorablemente.

4 Esta encuesta se aplicó entre agosto y octubre de 2017 y se encuestó a más de 13 mil personas mayores de 15 años a lo largo del país. El error muestral es de $4 \%$ y posee un 95\% de confianza. El trabajo en terreno fue realizado por el Centro Encuestas y Estudios Longitudinales de la Pontificia Universidad Católica de Chile.

5 La muestra se conformó por 4.176 casos y es representativa de la población mayor de 15 años, diferenciando en cada región por sexo, tramo de edad y nivel socioeconómico. El periodo de levantamiento de información fue desde el 16 de diciembre de 2008 al 10 de marzo de 2009. 
Los datos de la ENPC 2017 han demostrado que, aun cuando se han creado nuevos espacios culturales y una serie de políticas de fomento a la producción y circulación de la producción artística nacional, el acceso a bienes y servicios culturales no solo ha revelado una disminución notoria en los últimos diez años, sino que tampoco se ha observado una transformación en la estructura social de los que acceden. En otros términos, hay menos demanda por acceder a bienes y servicios culturales y, entre los que acceden, no ha cambiado su origen social y educativo.

Desde la medición de 2012 es posible advertir un decrecimiento importante de los accesos culturales, especialmente en términos de lectura de libros (en 2012 el 47\% de la población nacional declaró haber leído al menos un libro al año, y en 2017 ese porcentaje fue de $38,9 \%)$ y asistencia a espacios de exhibición de artes visuales. En este caso, en 2012 un 25\% de los chilenos asistió a una exposición de artes visuales en los últimos 12 meses, mientras que, según la encuesta 2017, esa cifra disminuyó a un 16\%. Lo mismo ocurrió en teatro: en 2012 el $17,8 \%$ presenció una obra de teatro en los últimos 12 meses, mientras que el 2017 esa cifra fue de 14,2\%. El único servicio cultural que mantiene una tendencia estable es el cine (entre ambos años no hay diferencias significativas: en 2012 un 45\%, mientras que en 2017 un 44\%).

Sumado a lo anterior, es especialmente preocupante lo que ocurre en el caso de bibliotecas y museos. Aun cuando se han realizado una serie de políticas destinadas a fomentar el acceso a estos espacios, así como la gestación de departamentos de educación y mediación cultural, y gratuidad, los valores de acceso se han mantenido bajos y decrecientes (de 18,2\% en 2012 a 17,4\% en 2017 para bibliotecas; de $24 \%$ a $20,5 \%$ en museos). En simple, y al ver estas estadísticas, la gran sorpresa es que, tras varios años de vigencia de políticas culturales en el país, la desigualdad en estos ámbitos no disminuye.

Ahora bien, si en la actualidad la educación artística se erige como una herramienta clave para la formación ciudadana y para generar en las personas el interés por la cultura y las artes (Oberta, 2015; Mincap, 2018b), resulta importante entonces aportar conocimientos empíricos sobre la materia. Análisis desarrollados desde la ENPCC 2009 han demostrado que el acceso a expresiones artísticas involucra otros fenómenos sociales, tales como la forma en que se concibe o reflexiona un 
país (Peters, 2012). Es decir, si reconocemos que las estructuras sociales siguen definiendo el acceso a las manifestaciones artístico-culturales y, por tanto, sus lógicas de comportamiento, resulta central avanzar más allá de esta constatación y preguntarnos qué otras dimensiones están relacionadas con el acceso cultural.

Frente al actual desafío de ampliar las posibilidades de discusión sobre el acceso cultural, es posible plantearse la siguiente pregunta: ¿Existe alguna afinidad electiva ${ }^{6}$ o una articulación de hechos relacionados entre el acceso cultural y las valoraciones democráticas, sociales y ciudadanas de los consumidores de cultura? La respuesta a esta interrogante, que ya ha sido profundizada con anterioridad (Güell \& Peters, 2012), permite demostrar con evidencia estadística que las personas que acceden a altos niveles de consumo cultural $-\mathrm{e}$ independiente de su nivel socioeconómico- manifiestan altos niveles de individuación, creen que la democracia es la mejor forma de gobierno, poseen alto nivel de tolerancia hacia la diferencia y establecen mayores vínculos sociales con su comunidad (Peters, 2010). Estos indicadores de civilidad demostraron el alto potencial que los bienes artísticos y culturales tienen para fomentar mayores niveles de reflexividad social.

Frente a estos avances analíticos, se vuelve imperioso establecer un vínculo con la educación artística. Efectivamente, y como hemos visto en la sección anterior, ella juega un rol fundamental en la medida en que fortalece los vínculos entre individuo y reflexividad social. Si bien en Chile algunos estudios han identificado los aportes que la educación artística ofrece a las personas (CNCA, 2013b; Mincap, 2018b), resulta interesante volver a trabajar la hipótesis de la afinidad electiva en el caso específico de la participación en talleres y/o clases artísticas por parte de los chilenos. Con este fin, utilizaremos la misma base de la ENPCC 2009 para explorar esta dimensión de análisis.

6 El concepto de "afinidades electivas" refiere no a relaciones causales, sino al vínculo que se produce entre dos dinámicas diferentes de la acción social - por ejemplo, entre capitalismo y puritanismo- y por la similitud de sus sentidos subjetivos y de sus finalidades. De la afinidad electiva entre dos fenómenos resulta su mutuo reforzamiento. En la versión weberiana se trata precisamente de afirmar el vínculo entre dos hechos o estructuras, no por referencia a alguna regla fija de causalidad independiente de las interpretaciones de los individuos, sino a la atribución que los actores hacen de su afinidad. Esto no significa que no existan regularidades estadísticas entre esos fenómenos. Por el contrario, las regularidades estadísticas son precisamente el indicio que conduce a interrogarse por las afinidades electivas subyacentes y a reconstruirlas (Weber, 2003). 
En aquellos años, cerca del $10 \%$ de la población reconocía que, al menos en el último año, había asistido a una o más clases o talleres de danza, interpretación musical y/o de canto, fotografía, teatro, teoría del arte, literatura y cine. Los que señalaron participar en mayor cantidad de talleres eran los que, al mismo tiempo, tenían mayores niveles de escolaridad (universitaria o estudiantes de enseñanza media humanista) e ingreso socioeconómico (principalmente ABC 1 y C2). Sumado a ello, se observó que los más jóvenes (entre 15 y 24 años) eran los que más talleres habían tomado en los últimos doce meses (esta tendencia se revierte en la medida en que la edad aumenta). A nivel de sexo, se observó una clara inclinación de las mujeres $(56,7 \%)$ por tomar más talleres que los hombres (43,3\%). Como es posible comprobar, la tendencia general del acceso a talleres fue relativamente similar a las tendencias generales del acceso a las manifestaciones artísticas: jóvenes, con alta escolaridad e ingresos económicos.

Ahora bien, al analizar según las valoraciones democráticas, sociales y ciudadanas de los participantes de talleres de educación artística es posible observar lo siguiente. Al consultarles a los participantes de los talleres: "Cuando se producen conflictos sociales, ¿qué debiera hacerse?", el 53,3\% de ellos respondió “Que se muestren los conflictos y aparezcan los problemas", mientras que el 45,2\%: "Evitar los conflictos, para que las cosas no pasen a mayores". Por el contrario, entre los que no participaron en ningún taller de educación artística, la tendencia se revierte: un $53,7 \%$ señaló "Evitar los conflictos, para que las cosas no pasen a mayores" y un 40,6\% señaló "Que se muestren los conflictos y aparezcan los problemas" (el 5,7\% de ellos no respondió o no sabía qué responder).

En la misma lógica, se consultó a los participantes de talleres artísticos lo siguiente: "Mirando el rumbo que ha tomado su vida, $i$ Ud. cree que ese rumbo ha sido principalmente el resultado de sus decisiones personales o de las circunstancias que le ha tocado vivir?" De ellos, un $62,3 \%$ respondió la primera opción (de sus decisiones personales), mientras que el $36,8 \%$ la segunda (las circunstancias que le ha tocado vivir). Entre los que no participaron en ningún taller las cifras cambian: un $50 \%$ se inclina por la primera opción, mientras que un $45,3 \%$ por la segunda. Esta dimensión, orientada a identificar los niveles de individuación de los chilenos -que identifica las posibilidades que la 
sociedad ofrece para la construcción de proyectos biográficos (Güell, Peters \& Morales, 2012)—, demuestra que una mayor participación en talleres de educación artística podría ayudar a percibir la propia vida con mayor autonomía y control. En otros términos que, a pesar de las barreras que la sociedad chilena impone a sus ciudadanos para desplegar sus proyectos vitales - por ejemplo, bajos niveles de protección social, baja calidad educacional, sistemas de salud desfinanciados, sistemas de transporte público deficientes, pensiones bajo la línea de la pobreza-, las personas que participan en talleres artísticos se inclinan a concebir su vida como una búsqueda permanente autorreflexiva. En efecto, gracias a que el individuo tiene capacidad de autodeterminación, es posible considerar los valores y las autoridades tradicionales de la sociedad como orientaciones que pueden someterse a reflexión, evaluación y elección personal, y no como acciones obligadas o impuestas desde la sociedad. En este sentido, con los resultados aquí expuestos se advierte que participar en talleres artísticos puede fortalecer los niveles de individuación de las personas.

Respecto de la dimensión "sociabilidad", a los participantes de talleres se les preguntó: "En el último mes, ¿ंcuántas veces Ud. ha sido invitado a la casa de amigos o invitado a salir?" Entre los que al menos habían participado en una actividad de educación artística en los últimos 12 meses, un 52,4\% señaló que "Más de 1 vez por semana", un $35,8 \%$ "2 o 3 veces al mes" y solo un 3,2\% afirmó que "Nunca". Por el contrario, entre los que no participaron de ningún taller, las cifras son bastante diferentes: un 28,6\% "Más de 1 vez por semana", 27,5\% "2 o 3 veces al mes" y un 22,7\% "Nunca". Al igual que las tendencias antes descritas, la participación en talleres artísticos demuestra una mayor lógica de valoración social que la de los no interesados en participar en ellos.

Si hasta ahora hemos analizado las dimensiones de conflictividad social, las lógicas de percepción de construcción biográfica y las instancias de sociabilidad, conviene preguntarse sobre los niveles de valoración de la democracia en el país. Frente a la pregunta “iCon cuál de las siguientes frases está Ud. más de acuerdo?: a) La democracia es preferible a cualquier otra forma de gobierno, b) Es mejor un gobierno autoritario que uno democrático y c) Da lo mismo un gobierno democrático que uno autoritario", los resultados no señalaron mayores dife- 
rencias entre ambos grupos. En ambos casos, la mayoría optó por la primera afirmación (más del 50\%).

Más allá de señalar que existe un vínculo directo entre estas dimensiones o percepciones socioculturales sobre la sociedad y el acceso a las instancias de educación artística, creemos importante plantear estas interrogantes y ampliar las preguntas sobre el fenómeno. Como queda de manifiesto, es interesante constatar que la participación en talleres de educación artística mantiene ciertas afinidades o hechos relacionados con otras variables de reflexividad social, tales como la valoración al conflicto, los niveles de sociabilidad y los procesos de reflexividad biográfica. Si bien es claro que existe una relación estructural entre ingreso, educación y edad, así como también una subrepresentación de los participantes de talleres o cursos de educación artística, lo que interesa destacar aquí es el ejercicio analítico-interpretativo sobre las potencialidades de la educación artística en la sociedad.

\section{Conclusión. Cruces y dilemas de la educación artística hoy}

Como señaláramos al principio de este artículo, la trayectoria histórica de la educación artística se ha caracterizado por acoger una serie de tensiones teóricas, políticas y culturales. Educación y arte se complementan, no tan solo como un marco de enseñanzas y aprendizajes, sino también para reflexionar sobre los significados culturales, identitarios y de sentido de una sociedad. Si en un principio su enfoque estuvo destinado a una utilidad práctica y/o técnica (en el dibujo, por ejemplo), en el presente es indudable reconocer la educación artística como marco general de pensamiento y cuestionamiento acerca de las diversas dimensiones de la realidad social, política, cultural, económica, ecológica, etcétera, de una comunidad social. Hoy, con la expansión ilimitada de las imágenes y la cultura visual, la sociedad se ve interpelada no solo a discutir las formas de circulación y comprensión de símbolos globales, sino también elaborar nuevas lógicas educativas sobre esos fenómenos.

Efectivamente, es importante destacar el hecho de que, entendido de modo amplio, acceder a las manifestaciones artísticas a través de las lógicas educativas formales e informales significa relacionarnos con una oferta ligada a infinitas experiencias estéticas (artes visuales, mú- 
sica, teatro, danza, literatura, cine), pero, al mismo tiempo, satisfacemos otras necesidades como la identificación grupal, nacional o multinacional, nos distinguimos socialmente (y simbólicamente), logramos sociabilidad con otros por medio de ritos (expresión), nos apropiamos de espacios públicos (prácticas) y, a la vez, participamos (en distintas formas culturales) en el mundo. En su conjunto, es necesario comprender la ecuación Arte + Educación + Sociedad (y todo lo que ello involucra: políticas culturales, planes y programas de educación, formación docente, esquemas de trabajo en el aula) por su amplitud de impacto sociocultural. Pero, además, por cómo genera en el sujeto enunciados de sentido que lo interpelan para pensar su condición en el mundo y sus proyectos biográficos, en una existencia cada vez más inserta en los circuitos mundiales y bajo las lógicas de la cultura visual.

Visto de esta forma, se comprende la educación artística como un dispositivo para pensar contextos. La experiencia artística no solo implica un ejercicio estético basado en procesos de ejecución artística, sino que, al mismo tiempo, permite pensar y discutir los entornos directos e indirectos de los individuos. Por esta razón, el arte también se comprende como una mediación en la estructura de poder. Los procesos y relaciones entre el arte y la educación construyen un territorio intermedio en el que se descentran los papeles tradicionales del orden hegemónico. En ese sentido, los individuos no son solo meros receptores de ese saber, sino que lo construyen, lo interpretan (reflexionan) y lo interpelan. Y si lo hacen desde y con la experiencia artística, no solo la educación gana un aliado, sino la sociedad en su conjunto.

\section{Referencia}

Acaso, M. y Megías, C. (2017). Art Thinking. Cómo el arte puede transformar la educación. Madrid: Editorial Paidós.

Alvarado, P. y Marini, G. (2020). Educación artística y políticas públicas educacionales. Revista MGC, 16, 20-29.

Bamford, A. (2009). El factor ;Wuau! El papel de las artes en la educación. Un estudio internacional sobre el impacto de las artes en la educación. Barcelona: Octaedro.

Barrett, J. (2012). Museums and the public sphere. Oxford: Wiley-Blackwell. 
Burnham, R. \& Kai-Kee, E. (2014). Teaching in the Art Museum: Interpretation as Experience. Los Angeles, California: Getty.

Consejo Nacional de la Cultura y las Artes. (2009). Segunda Encuesta Nacional de Participación y Consumo Cultural. Recuperado de http://observatorio.cultura.gob.cl/index.php/encuestasde-participacion-cultural/

Consejo Nacional de la Cultura y las Artes. (2012). Tercera Encuesta Nacional de Participación y Consumo Cultural. Recuperado de http://observatorio.cultura.gob.cl/index.php/encuestas-departicipacion-cultural/

Consejo Nacional de la Cultura y las Artes. (2013a). Completando el modelo educativo. 12 prácticas educación artísticas en Chile. Recuperado de https://www.cultura.gob.cl/wp-content/ uploads/2013/05/libro-completando-modelo-educativo. pdf

Consejo Nacional de la Cultura y las Artes. (2013b). Estudio sobre el aporte de la educación artística a las competencias laborales transversales. Recuperado de http://observatorio.cultura. gob.cl/index.php/2021/01/30/estudio-sobre-el-aporte-dela-educacion-artistica-a-las-competencias-laborales-transversales/

Dewey, J. (1980). Art as experience. New York: Perigee Books.

Efland, A. (1990). A History of Art Education: Intellectual and Social Currents in Teaching the Visual Arts. New York \& London: Teachers College Press.

Efland A., Freedman, K. \&y Stuhr, P. (1996). La educación en el arte posmoderno. Barcelona: Paidós.

Errázuriz, L. (1994). Historia de un área marginal: la enseñanza artística en Chile 1797-1993. Santiago, Chile: Ediciones Universidad Católica de Chile.

Fleming, M, Bresler, L. \& O'Toole, J. (2015). The Routledge International Handbook of the Arts and Education. New York: Routledge.

Gaete, M., Miranda, L. y Ramírez, M. (2007). Arte y Filosofía en el currículo escolar. Entre el desarraigo y el olvido. Santiago, Chile: Ediciones Facultad de Filosofía y Humanidades, Universidad de Chile.

Gardner, H. (1990). Educación artística y desarrollo humano. Barcelona: Paidós. 
Güell, P. y Peters, T. (eds.). (2012). La trama social de las prácticas culturales. Sociedad y subjetividad en el consumo cultural de los chilenos. Santiago, Chile: Ediciones Universidad Alberto Hurtado.

Güell, P., Peters, T. y Morales, R. (2012). Individuación y consumo cultural: las afinidades electivas. En P. Güell y T. Peters, La trama social de las prácticas culturales (pp. 21-49). Santiago, Chile: Universidad Alberto Hurtado.

Hermosilla, D. (2020). La posibilidad de los aprendizajes. Experiencias del programa Centros de Creación (Cecrea). Revista MGC, $16,49-57$

Hernández, F. (2007).Espigador@s de la cultura visual: otra narrativa para la educación de las artes visuales. Barcelona: Octaedro.

Martineau, J. (2017). Culture in the age of acceleration, hypermodernity, and globalized temporalities. The Journal of Arts Management, Law, and Society, 47(4): 218-229

Ministerio de las Culturas, las Artes y el Patrimonio. (2018a). Encuesta Nacional de Participación Cultural en Chile 2017. Recuperado de http://observatorio.cultura.gob.cl/index.php/encuestas-de-participacion-cultural/

Ministerio de las Culturas, las Artes y el Patrimonio. (2018b). Arte, educación y ciudadanía. 2013-2018. Recuperado de https:// www.cultura.gob.cl/publicaciones/arte-educacion-y-ciudadania-2013-2018/

Miranda, L. y Espinoza, M. (2015). El currículo de artes visuales en la educación chilena. Revista Docencia, 57, 17-27

Mirzoeff, N. (2003). Una introducción a la cultura visual. Barcelona: Paidós Ibérica.

Naughton, C., Biesta, G. \& Cole, D. (2018). Art, Artists and Pedagogy: Philosophy and the Arts in Education. New York: Routledge.

Nervi, M. (2004). Los saberes de la Escuela. Análisis de la renovación disciplinaria en la reforma curricular 1996-2002. Santiago, Chile: Editorial Universitaria.

Oberta, A. (ed.). (2015). Educación Artística: Propuestas, Investigación y Experiencias Recientes. Santiago, Chile: Ediciones Universidad Alberto Hurtado.

Ossa, C. (ed.). (2017). Escena de frontera: educación artística, currículo y política. Santiago, Chile: Universidad de Chile. 
Ossa, C. (2016). El ego explotado. Capitalismo cognitivo y precarización de la creatividad. Santiago: Facultad de Artes, Universidad de Chile.

Peters Núñez, T. (2010). La afinidad electiva entre consumo cultural y percepción sociocultural: El caso de Chile. Signo y Pensamiento, 29(57), 216-235.

Peters Núñez, T. (2012). Nuevos desplazamientos en la investigación en cultura: aportes de la segunda Encuesta Nacional de Participación y Consumo Cultural de Chile. Revista Persona y Sociedad, XXVI(1), 87-112.

Rojas, P. y Del Valle, N. (2020). Educación artística en Chile: apuntes sobre sus condiciones históricas e institucionales. Revista $M G C, 16,8-19$

UNESCO. (2010). La Agenda de Seúl: Objetivos para el desarrollo de la educación artística. Recuperado de http://www.unesco.org/ new/es/culture/themes/creativity/arts-education/officialtexts/development-goals/

UNESCO (2006). Hoja de Ruta para la Educación Artística. Construir capacidades creativas para el siglo XXI. Recuperado de http://www.unesco.org/new/es/culture/themes/creativity/ arts-education/official-texts/road-map/

Villegas, I. ed. (2017). Dibujo en Chile (1797-1991). Variaciones epistemológicas, aplicaciones profesionales. Santiago, Chile: Lom.

Weber, M. (2003). La ética protestante y el espíritu del capitalismo. México: Fondo de Cultura Económica.

Zamorano, P. (2007). Educación artística en Chile: Fernando Álvarez de Sotomayor, Juan Francisco González y Pablo Burchard, tres maestros emblemáticos. Revista Atenea, 495, 185-211 